\title{
Rapid epigenetic adaptation to uncontrolled heterochromatin spreading
}

\author{
Jiyong Wang, Bharat D Reddy, Songtao Jia* \\ Department of Biological Sciences, Columbia University, New York, United States
}

*For correspondence: jia@ biology.columbia.edu

Competing interests: The authors declare that no competing interests exist.

Funding: See page 14

Received: 19 December 2014 Accepted: 12 March 2015

Published: 16 March 2015

Reviewing editor: Ali Shilatifard, Northwestern University Feinberg School of Medicine, United States

Copyright Wang et al. This article is distributed under the terms of the Creative Commons Attribution License, which permits unrestricted use and redistribution provided that the original author and source are credited.

\begin{abstract}
Heterochromatin, a highly compact chromatin state characterized by histone H3K9 methylation and HP1 protein binding, silences the underlying DNA and influences the expression of neighboring genes. However, the mechanisms that regulate heterochromatin spreading are not well understood. In this study, we show that the conserved Mst2 histone acetyltransferase complex in fission yeast regulates histone turnover at heterochromatin regions to control heterochromatin spreading and prevents ectopic heterochromatin assembly. The combined loss of Mst2 and the JmjC domain protein Epe1 results in uncontrolled heterochromatin spreading and massive ectopic heterochromatin, leading to severe growth defects due to the inactivation of essential genes. Interestingly, these cells quickly recover by accumulating heterochromatin at genes essential for heterochromatin assembly, leading to their reduced expression to restrain heterochromatin spreading. Our studies discover redundant pathways that control heterochromatin spreading and prevent ectopic heterochromatin assembly and reveal a fast epigenetic adaptation response to changes in heterochromatin landscape.
\end{abstract}

DOI: 10.7554/eLife.06179.001

\section{Introduction}

Eukaryotic genomic DNA is folded with histones and non-histone proteins in the form of chromatin, which regulates every aspect of DNA metabolism, including transcription, replication, recombination, and DNA damage repair. Chromatin is classified into euchromatin, which is gene rich and actively transcribed, and heterochromatin, which is gene poor and highly compacted (Grewal and Jia, 2007). Heterochromatin preferentially forms at repetitive DNA elements in order to limit transcription and recombination at these regions to maintain genome integrity. It also forms at developmentally regulated genes to regulate their expression in response to developmental cues and external stimuli. Heterochromatin tends to spread into neighboring regions, leading to the inactivation of genes in a sequence-independent manner (Talbert and Henikoff, 2006; Wang et al., 2014). Therefore, the sites of heterochromatin formation and extent of heterochromatin spreading need to be tightly controlled to prevent improper gene silencing, and misregulation of heterochromatin assembly has been linked to many human diseases, especially various types of cancers (Geutjes et al., 2012).

Heterochromatic regions generally have distinct chromatin signatures such as histones that are hypoacetylated and methylated at histone $\mathrm{H} 3$ lysine 9 (H3K9me), and the enrichment of HP1 family proteins (Rea et al., 2000; Bannister et al., 2001; Lachner et al., 2001; Nakayama et al., 2001). Formation of heterochromatin requires the concerted actions of a diverse group of histone-modifying proteins, such as H3K9 methyltransferases and histone deacetylases (HDACs), and is divided into three distinct steps: establishment, spreading, and maintenance (Grewal and Moazed, 2003; Rusche et al., 2003). Heterochromatin is established at nucleation centers through the targeting of histonemodifying activities by transcription factors or non-coding RNAs (Cohen and Jia, 2014). Subsequently, heterochromatin spreads into neighboring regions, mostly via a network of interactions among chromatin proteins, resulting in the formation of large heterochromatin domains independent of the underlying DNA sequences (Talbert and Henikoff, 2006; Cohen and Jia, 2014). Once these 
eLife digest The DNA in the nucleus of a cell is wrapped around histone proteins to form a compact structure known as chromatin. Chromatin's structure can control how the genes in DNA are expressed. Loosely packed chromatin contains active genes, whereas densely packed chromatin (also called 'heterochromatin') contains silenced genes that are not expressed. The assembly of DNA into heterochromatin needs to be carefully controlled. Otherwise, the DNA next to heterochromatin regions can become densely packed as well (via a process called 'heterochromatin spreading'), and the genes within this DNA are incorrectly silenced. Incorrect gene silencing is often associated with diseases such as cancer.

Cells add chemical groups onto the histone proteins to influence how chromatin is compacted. Densely packed chromatin contains histones with many methyl groups but few acetyl groups. A protein called Epe1, which potentially removes methyl groups, helps to prevent heterochromatin spreading in yeast cells. Wang et al. found that an enzyme called Mst2, which adds acetyl groups onto histones, also limits heterochromatin spreading and prevents extra heterochromatin from assembling at undesirable locations.

Wang et al. then generated yeast cells that lacked both Epe1 and Mst2. At first, these cells were sickly and unable to grow, because several essential genes were incorrectly silenced due to rampant heterochromatin spreading. However, the cells quickly overcame this growth defect by gaining an additional mutation. Normally mutations occur through changes in DNA sequences. However, Wang et al. found that the cells acquired this mutation by packing a gene required for heterochromatin assembly into heterochromatin. This in turn stopped more chromatin from becoming packed too densely. Changes to chromatin can also be passed on to the yeast's offspring, and such a change could help the offspring to better cope with changes in heterochromatin levels. Future work could test how often inheritable changes to chromatin modification help organisms adapt to environmental stresses, or if similar changes allow cancer cells to become tolerant to anticancer drugs.

DOI: 10.7554/eLife.06179.002

domains are formed, they can maintain themselves also through interactions among chromatin proteins even in the absence of the initiation signal (Moazed, 2011; Ragunathan et al., 2014).

The formation of heterochromatin has been extensively studied in fission yeast, which uses highly conserved histone-modifying enzymes and chromatin proteins for heterochromatin assembly, such as the SUV39 family histone H3K9 methyltransferase Clr4, the HP1 homologue Swi6, and HDACs Sir2 and Clr3 (Grewal and Jia, 2007). There are four types of heterochromatin identified in fission yeast: constitutive heterochromatin at repeat regions such as centromeres, telomeres, and the silent matingtype region (Grewal and Jia, 2007); facultative heterochromatin islands at a subset of meiotic genes (Hiriart et al., 2012; Zofall et al., 2012; Tashiro et al., 2013; Egan et al., 2014); HOODs (heterochromatin domains) at sexual differentiation genes and retrotransposons in response to the misregulation of the exosome (Yamanaka et al., 2013); and transient heterochromatin at convergent genes (Gullerova and Proudfoot, 2008). These locations use distinct pathways to recruit histonemodifying activities to form heterochromatin.

The establishment of constitutive heterochromatin at repetitive DNA elements requires the RNA interference (RNAi) pathway, a phenomenon also vastly conserved in eukaryotes (Moazed, 2009; Lejeune and Allshire, 2011; Castel and Martienssen, 2013). The DNA repeats are transcribed and the transcripts are processed by the RNAi machinery into small interfering RNAs (siRNAs), which target the Clr4 complex (CLRC, consisting of Clr4, Cul4, Rik1, Raf1, and Raf2) to repeat regions to initiate $\mathrm{H} 3 \mathrm{~K} 9 \mathrm{me}$. In addition, DNA binding factors, such as telomeric shelterin and stress-activated ATF/CREB family proteins Atf1/Pcr1, also directly recruit histone-modifying activities to establish constitutive heterochromatin at telomeres and the silent mating-type region, respectively (Jia et al., 2004; Kim et al., 2004; Kanoh et al., 2005; Tadeo et al., 2013). The formation of facultative heterochromatin islands at meiotic genes requires RNA binding protein Mmi1, Zinc finger protein Red1, and the exosome (Hiriart et al., 2012; Zofall et al., 2012; Tashiro et al., 2013; Egan et al., 2014). Mmi1 binds to RNA transcripts containing DSR (determinant of selective removal) sequences and recruits the RNA-induced transcriptional silencing (RITS) complex and the Red1-Mtl1 complex, which directly interacts with Clr4 complex, to initiate H3K9me at meiotic genes (Harigaya et al., 2006; 
Zofall et al., 2012; Lee et al., 2013; Egan et al., 2014). HOODs are formed at sexual differentiation genes and retrotransposons in response to exosome malfunction or changes in environmental conditions and requires RNAi, polyA polymerase Pla1, and PolyA binding protein Pab2 (Lee et al., 2013; Yamanaka et al., 2013). Convergent genes generate overlapping transcripts during the G1 phase of the cell cycle, which induce the formation of transient heterochromatin through the RNAi pathway (Gullerova and Proudfoot, 2008).

The spreading of heterochromatin requires Swi6 and the chromodomain of Clr4, both of which bind to H3K9me and position Clr4 to methylate neighboring nucleosomes (Hall et al., 2002; Zhang et al., 2008; Al-Sady et al., 2013). The reiteration of H3K9 methylation and recruitment of Clr4 by H3K9me, either directly through the chromodomain or indirectly through Swi6, results in the 'inchworm'-like spreading of heterochromatin from nucleation centers into large chromosome domains (Talbert and Henikoff, 2006; Wang et al., 2014). Some heterochromatin regions are flanked by DNA sequences termed boundary elements, which block heterochromatin spreading (Wang et al., 2014). In other cases, heterochromatin borders are determined by the local balance of heterochromatin and euchromatin proteins, which tends to differ between cells. Therefore, precise regulation of heterochromatin spreading is essential to maintain stable gene expression profiles.

One of the best-known negative regulators of heterochromatin spreading is Epe1 as epe $1 \Delta$ results in heterochromatin spreading beyond its normal boundaries as well as ectopic heterochromatin formation (Zofall and Grewal, 2006; Trewick et al., 2007; Zofall et al., 2012; Ragunathan et al., 2014). Loss of Epe1 also bypasses RNAi for pericentric heterochromatin assembly by strengthening heterochromatin spreading (Trewick et al., 2007). Epe1 contains a JmjC domain, which is frequently associated with histone demethylase activity. Although no demethylase activity has been detected for Epe1 (Tsukada et al., 2006), genetic evidence is consistent with Epe1 being a H3K9 demethylase and conserved catalytic residues are essential for Epe1 function (Trewick et al., 2007; Ragunathan et al., 2014).

The Mst2 complex is similar in composition to budding yeast NuA3 and mammalian HBO1/MOZ/ MORF complexes (Wang et al., 2012). It is a highly specific histone H3K14 acetyltransferase that cooperates with Gcn5 to regulate global H3K14 acetylation levels (Nugent et al., 2010; Wang et al., 2012). The formation of heterochromatin is negatively correlated with H3K14 acetylation (Sugiyama et al., 2007; Motamedi et al., 2008), and mst2 $\Delta$ bypasses the requirement of the RNAi pathway for pericentric heterochromatin assembly through modulating H3K14ac levels at heterochromatin (Reddy et al., 2011). Moreover, mst2 $\Delta$ strengthens silencing at telomeres (Gomez et al., 2005). These results suggest that Mst2 complex functions to antagonize heterochromatic silencing, although the mechanism by which it affects heterochromatin assembly is unknown. The ability to bypass RNAi requires ablating the enzymatic activity of the Mst2 complex (Reddy et al., 2011). It was proposed that Mst2-mediated H3K14 acetylation regulates histone turnover at heterochromatin regions and the loss of such activity preserves parental histone modifications to promote heterochromatin maintenance (Reddy et al., 2011), although the ability of Mst2 to regulate histone turnover has not been directly tested.

In this study, we show that Mst2 regulates histone turnover at heterochromatin regions and that loss of Mst2 results in heterochromatin spreading at telomeres and heterochromatin islands where

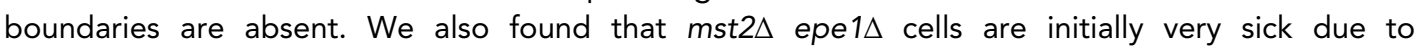
heterochromatin spreading-mediated inactivation of essential genes, suggesting that Mst2 and Epe1 function redundantly in regulating heterochromatin spreading. Interestingly, these cells quickly recover by forming ectopic heterochromatin at the clr4 $4^{+}$locus to mitigate the negative effects of heterochromatin. Disrupting heterochromatin assembly at the clr4 $4^{+}$locus results in ectopic heterochromatin formation at the rik $1^{+}$locus, which encodes another subunit of the $\mathrm{Clr} 4$ complex required for $\mathrm{H} 3 \mathrm{~K} 9 \mathrm{me}$. These results demonstrate that promiscuous heterochromatin assembly generates epigenetic mutations that provide fast adaptions to heterochromatin stress.

\section{Results}

\section{Mst2 regulates histone turnover at heterochromatin}

To directly examine the role of the Mst2 complex in regulating histone turnover, we generated a Flagtagged version of histone $\mathrm{H} 3$ driven by the urg1 promoter at the endogenous urg $1^{+} \operatorname{locus}$, which can be quickly induced by the addition of uracil into the growth medium at levels far below the endogenous histone H3 (Watt et al., 2008) (Figure 1A). To prevent replication-dependent histone incorporation, we blocked the cell cycle with hydroxyl urea (HU) before induction of $\mathrm{H} 3$-Flag 
A

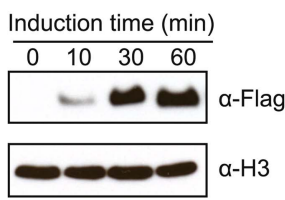

B

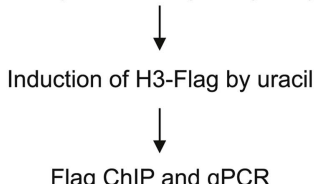

Flag ChIP and qPCR

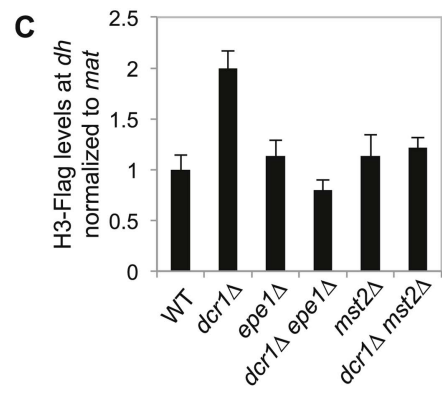

$\mathbf{F}$
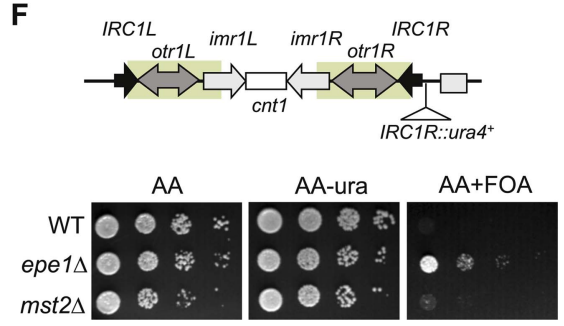

D

Chr I
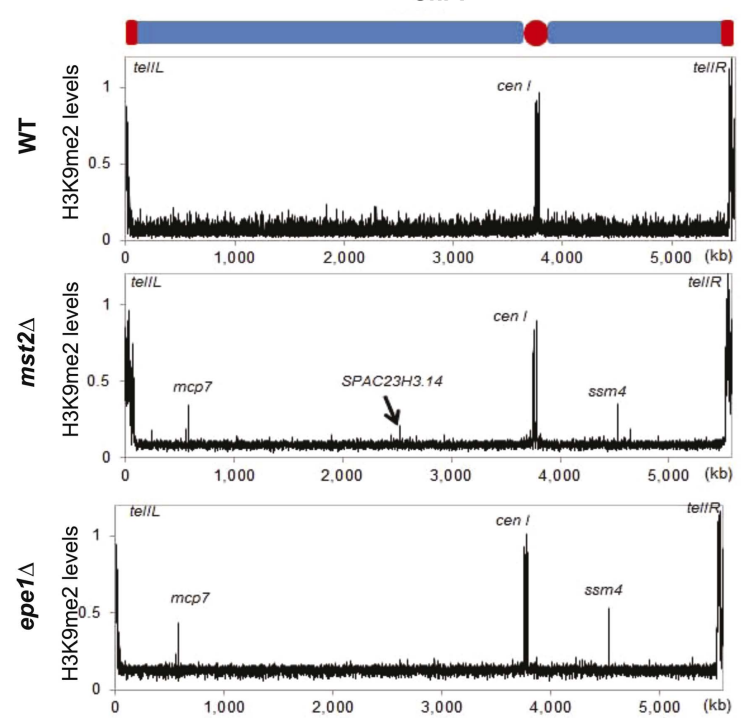

Chr II
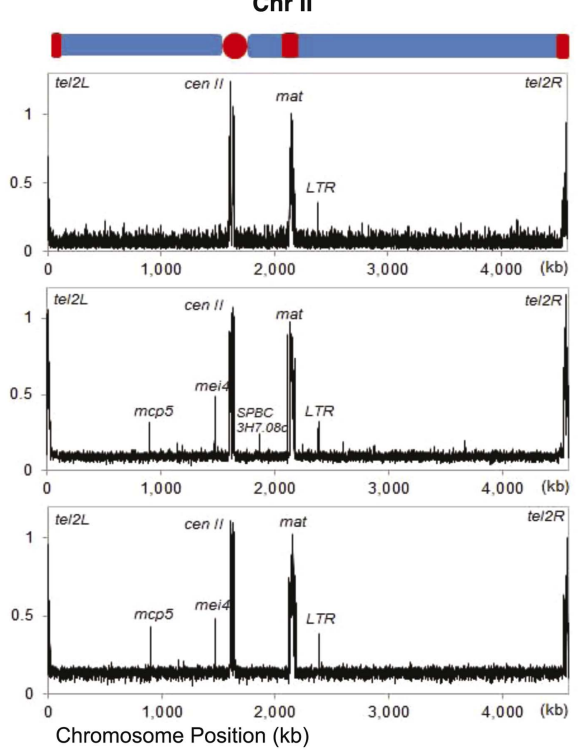

Chr III

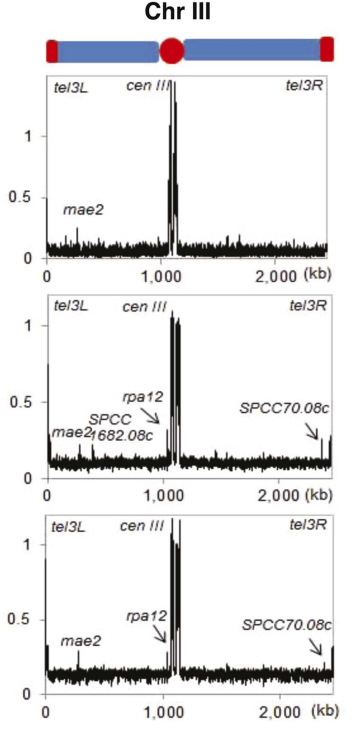

E
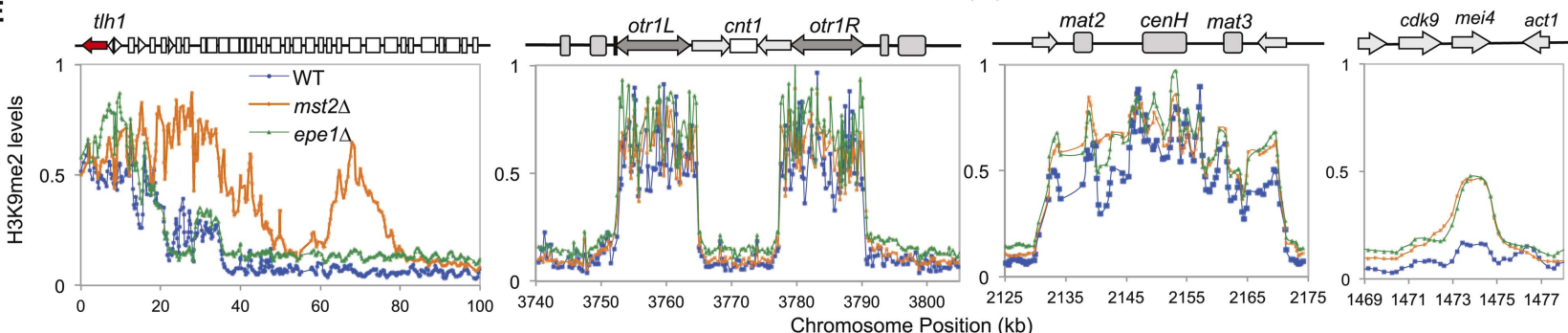

Figure 1. Mst2 counteracts heterochromatin assembly. (A) Western blot analysis of H3-Flag levels. Samples were taken at indicated times after the addition of uracil, and Western blot analyses were performed with Flag and $\mathrm{H} 3$ antibodies. (B) Schematic diagram of the histone turnover assay. (C) Enrichment of $\mathrm{H} 3-$ Flag at pericentric $d h$ sequence as an indicator of histone turnover rates. The values are normalized to a region within the silent mating-type locus with background histone turnover (Aygun et alo, 2013). Error bars represent standard deviation of three experiments. (D) ChIP-chip analyses of H3K9me2 levels across the genome. (E) ChIP-chip data of H3K9me2 levels around the telomere IL, centromere I, the silent mating-type region, and the mei4 ${ }^{+}$locus. (F) Mst2 is not required for boundary function at IRC1R. Serial dilution analysis were performed to measure the expression of IRC1R:::ura4+ reporter.

DOI: 10.7554/eLife.06179.003

The following figure supplement is available for figure 1:

Figure supplement 1. ChIP-chip data of H3K9me2 levels around centromere II, centromere III, telomere $1 \mathrm{R}$, telomere $2 \mathrm{~L}$, and telomere $2 \mathrm{R}$. DOI: 10.7554/eLife.06179.004

expression (Figure 1B). We found that pericentric $d$ h repeat was associated with lower amounts of H3-Flag in wild-type cells compared with RNAi mutant dcr1 $\Delta$ (Figure 1C), suggesting that histone turnover rates increase when heterochromatin is compromised. In addition, the incorporation of $\mathrm{H} 3-$ Flag was reduced in epe1 $1 \Delta \mathrm{dcr} 1 \Delta$ cells, as observed previously (Figure 1C) (Aygun et al., 2013). In mst2 $\Delta$ dcr1 $\Delta$ cells, H3-Flag incorporation was reduced to wild-type levels (Figure 1C), suggesting that the Mst2 complex indeed regulates histone turnover at heterochromatin. 
To further examine the role of the Mst2 complex in regulating heterochromatin assembly, we performed Chromatin Immunoprecipitation coupled with DNA microarray (ChIP-chip) analyses of H3K9me2 levels across the fission yeast genome. In wild-type cells, H3K9me2 was mainly present at centromeres, telomeres, and the silent mating-type region (Figure 1D). There were also a few heterochromatic islands with low levels of H3K9me2 (Figure 1D). Although less heterochromatic islands were identified compared to a recent study (Zofall et al., 2012), our results are consistent with that of an earlier one (Cam et al., 2005). The discrepancies might be caused by the use of batches of antibody with different sensitivity or different data processing methods. In mst2 $\Delta$ cells, constitutive heterochromatin domains at centromeres and the silent mating-type region were in good agreement with wild-type cells, but telomeric heterochromatin showed significant spreading into chromosome arms (Figure 1D,E and Figure 1-figure supplement 1), consistent with previous findings that mst2 $\Delta$ strengthens silencing at telomeres (Gomez et alı, 2005). Interestingly, there are a number of additional small H3K9me2 peaks scattered across the genome, most of which are also present in epe1 $1 \Delta$ cells (Figure 1D,E, and Supplementary file 1) (Zofall et al., 2012). Therefore, Mst2 also prevents ectopic heterochromatin assembly, similar to Epe1. We observed only minor heterochromatin spreading in telomeric regions in epe1 $1 \Delta$ cells compared with a previous study (Zofall et al., 2012), which might be due to the presence of two epigenetically stable subpopulations of cells with different effects on heterochromatin assembly (Trewick et al., 2007).

The difference between pericentric regions, telomeres, and heterochromatin islands is the presence of well-defined boundary elements at pericentric regions that block heterochromatin spreading (Wang et al., 2014). We found that mst2 $\Delta$ has no effect on boundary activity of an inverted repeat at the pericentric region, $I R C 1 R$, which requires Epe1 and the double bromodomain protein Bdf2 for function (Figure 1F) (Wang et al., 2013), suggesting that Mst2 regulates heterochromatin spreading only in the absence of boundaries.

\section{Misregulation of heterochromatin affects the fitness of mst2 $\Delta$ epe1 $\Delta$ cells}

Since mst2 $\Delta$ and epe1 $\Delta$ have similar phenotypes in heterochromatin assembly and each bypasses the RNAi pathway for pericentric heterochromatin functions (Trewick et al., 2007; Reddy et al., 2011), we generated mst2 $\Delta$ epe $1 \Delta$ cells to examine their epistatic relationship. All freshly generated mst2 $\Delta$ epe $1 \Delta$ cells formed very small colonies, suggesting a strong negative genetic interaction between these two mutants (Figure 2A and Figure 2-figure supplement 1), consistent with high throughput epistasis mapping (Roguev et al., 2008; Ryan et alo, 2012). Moreover, abolishing the enzymatic activity of Mst2 (mst2-E274Q or nto1 1 ) or Epe1 (epe1-H374A and epe1-Y307A) resulted in similar sickness (Figure 2-figure supplement 1), suggesting that the enzymatic activities of Mst2 and Epe1 have redundant functions. Double mutant of mst2 $\Delta$ bdf2 $\Delta$ had no defects in growth (Figure 2-figure supplement 1), suggesting that the boundary activity of Epe1 is not involved in genetic interaction with Mst2.

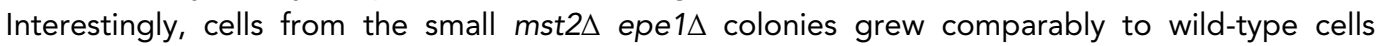
(Figure 2B,C), suggesting that the accumulation of either a genetic or more intriguingly, an epigenetic suppressor leads to quick and persistent production of normally growing mst $2 \Delta$ epe $1 \Delta$ cells. We crossed independent clones of recovered mst2 $\Delta$ epe $1 \Delta$ cells (mst2 $\Delta$ epe $1 \Delta^{*}$, which denotes the presence of a suppressor) and found that all resulting progenies grew normally from the beginning (Figure 2D). Moreover, when we crossed mst2 $\Delta$ epe $1 \Delta^{*}$ cells with wild-type cells, half of the resulting mst2 $\Delta$ epe $1 \Delta$ colonies were small and the other half were normal (Figure $2 E$ ), suggesting that changes associated with a single genomic locus was responsible for the recovery of these cells and also ruling out the possibility that the initial growth defects were the result of these cells going through meiosis.

To identify the suppressor, we performed two successive rounds of crosses to introduce mst $2 \Delta$ and epe $1 \Delta$ into the fission yeast deletion library and measured the initial growth of triple mutants before accumulation of a suppressor (Figure 2F). Interestingly, a number of heterochromatin assembly mutants allowed robust growth of $m s t 2 \Delta$ epe $1 \Delta$ cells. Such mutants included deletions of components of the CLRC histone H3K9 methyltransferase complex (clr4 $\Delta$, raf1 $\Delta$, and raf2 $\Delta$ ), an HP1 protein (swi6 $\Delta$ ), and histone deacetylases (sir2 $\Delta$ and clr3 $\Delta$ ) (Figure $2 G$ and Supplementary file 2). In contrast, none of the RNAi factors were identified in our screen. Individual crosses also confirmed that heterochromatin mutants conferred normal growth to mst2 $\Delta$ epe $1 \Delta$ cells (Figure $2 \mathrm{H}$ and Figure 2-figure supplement

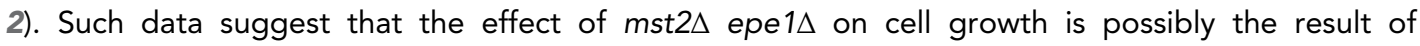
misregulation of heterochromatin. 
A

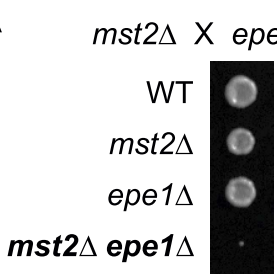

D

$m s t 2 \Delta$ epe $1 \Delta^{*} \mathrm{X}$ mst2 2 epe $1 \Delta^{*}$

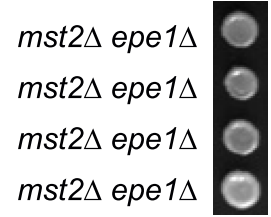

$F$

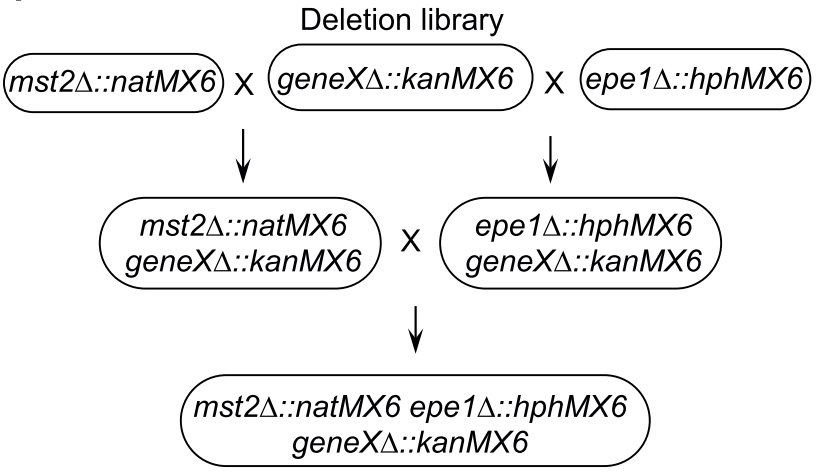

G

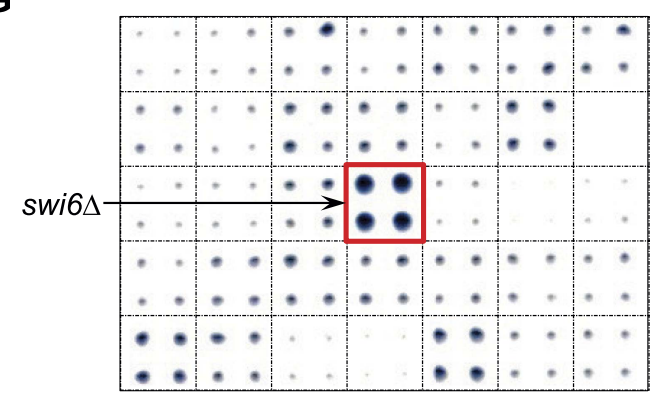

B

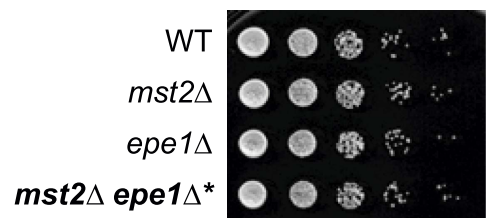

E

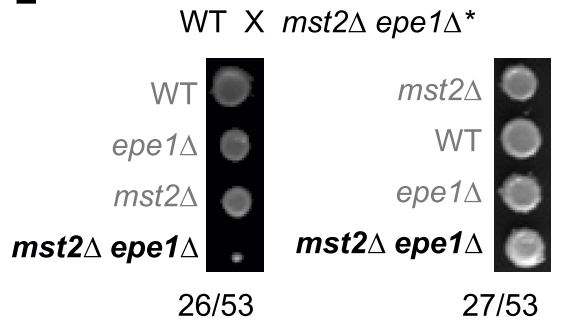

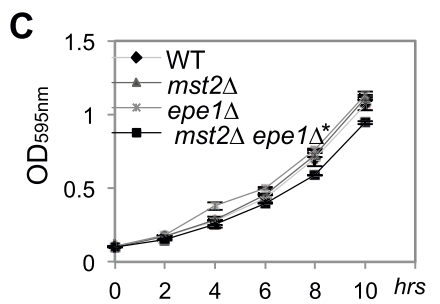

H
$c / r 4 \Delta$ epe $1 \Delta \mathrm{X} c \mathrm{cl} 4 \Delta \mathrm{mst} 2 \Delta$
$c / r 4 \Delta$ $m s t 2 \Delta c / r 4 \Delta$ epe1 $1 \Delta$ clr4 40 mst2 $\Delta$ epe1 $\Delta$ clr4 $\triangle$ O

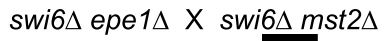

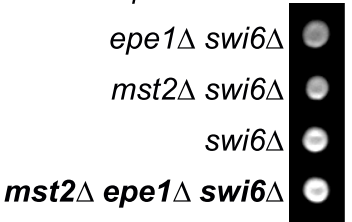

Figure 2. A suppressor mutation confers normal growth of mst $2 \Delta$ epe $1 \Delta$ cells. (A, D, E, H) Tetrad dissection analysis of the indicated genetic crosses. Pictures are examples of colonies derived from the same tetrad containing all individual genotypes, after one replication for a total of 6 days growth. (B) Serial dilution analysis of indicated strains. Cells were grown in rich medium overnight before dilution analyses were performed. (C) The growth curve of indicated strains. (F) Workflow to introduce mst2 $\Delta$ and epe1 $\Delta$ into the deletion library. (G) Left, a representative image of colony growth was shown. Middle, colonies were assigned scores between 0 and 3, as indicated. Right, list of identified heterochromatin mutants that confer fast growth.

DOI: 10.7554/eLife.06179.005

The following figure supplements are available for figure 2:

Figure supplement 1. Tetrad dissection analysis of the indicated genetic crosses. DOI: 10.7554/eLife.06179.006

Figure supplement 2. Tetrad dissection analysis of indicated genetic crosses.

DOI: 10.7554/eLife.06179.007 


\section{Increased heterochromatin spreading is responsible for the initial growth defects of mst2 $\Delta$ epe $1 \Delta$ cells}

To determine whether there are any global changes in heterochromatin organization, we decided to perform ChIP-chip analysis of H3K9me2 levels across the genome in mst2 $\Delta$ epe1 $\Delta$ cells. However, the quick generation of epigenetic suppressors in mst2 2 epe $1 \Delta^{*}$ cells prevented us from directly testing the reason for the initial growth defects. Because $\mathrm{H} 3 \mathrm{~K} 9$ me functions upstream of Swi6 localization and the silencing function of $\mathrm{H} 3 \mathrm{~K} 9$ me requires Swi6, we reasoned that examining $\mathrm{H} 3 \mathrm{~K} 9 \mathrm{me} 2$ levels in mst2A epe1 $\Delta$ swib $\Delta$ cells might show the misregulation of heterochromatin assembly that resembles early stages mst $2 \Delta$ epe $1 \Delta$ cells. Indeed, in mst2 $\Delta$ epe $1 \Delta$ swib $\Delta$ cells, the H3K9me2 domains at constitutive heterochromatin regions such as centromeres showed significant expansion, even when boundary elements are present (Figure $3 \mathrm{~A}, \mathrm{~B}$ ). In addition, many additional peaks of $\mathrm{H} 3 \mathrm{~K} 9 \mathrm{me} 2$ were detected across the genome, at levels comparable to constitutive heterochromatin domains (Figure $3 A, B$, Figure 3-figure supplement 1, and Supplementary file 1). Most, but not all, of these additional sites correspond to previously described heterochromatin islands. Compared to wild-type, mst2 $\Delta$, or epe $1 \Delta$ cells, these heterochromatic islands were also greatly expanded (Figure 3B and Figure 3-figure supplement 1). Given that Swib also contributes to heterochromatin spreading (Hall et alo, 2002; Al-Sady et al., 2013), heterochromatin probably spreads over even longer distances when Swi6 is present. Interestingly, essential genes reside within or near some of the expanded H3K9me2 domains (Figure 3B and Figure 3-figure supplement 1), suggesting that misregulation of heterochromatin spreading inactivates essential genes and causes the initial sickness of mst $2 \Delta$ epe $1 \Delta$ cells.

If heterochromatin spreading is the cause of the initial growth defects of mst $2 \Delta$ epe $1 \Delta$ cells, we expect that mutations blocking heterochromatin spreading will abolish such an effect. The spreading of heterochromatin requires Swib as well as the chromodomain of Clr4, which binds to pre-existing H3K9me to allow the modification of adjacent nucleosomes (Hall et al., 2002; Zhang et al., 2008;

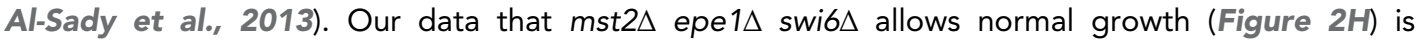
consistent with such a hypothesis. However, Swib is required for heterochromatin spreading as well as heterochromatin-mediated silencing, making it difficult to definitively assess the contribution of heterochromatin spreading in this process. We therefore tested a mutation within the $\mathrm{Clr} 4$ chromodomain, W31G, which affects the binding of Clr4 to H3K9me to block heterochromatin spreading (Zhang et alo, 2008). Indeed, mst2 $\Delta$ epe1 $1 \Delta$ clr4-W31G cells showed no initial growth defects (Figure $3 C$ ) and heterochromatin expansion is prevented as indicated by ChIP analysis of H3K9me2 levels outside of centromere I boundary and at the mei4+ locus (Figure 3D).

\section{Ectopic heterochromatin at the clr4 ${ }^{+}$locus promotes adaption of mst2 $\Delta$ epe $1 \Delta$ cells}

ChIP-chip analysis also showed that the patterns and levels of H3K9me2 in mst2 $\Delta$ epe $1 \Delta^{*}$ cells were more similar to those in wild-type cells with high levels of $\mathrm{H} 3 \mathrm{~K} 9 \mathrm{me} 2$ at constitutive heterochromatic regions and low levels of $\mathrm{H} 3 \mathrm{~K} 9 \mathrm{me} 2$ at heterochromatic islands, and much less heterochromatin spreading compared with mst2 $2 \Delta$ epe $1 \Delta$ swib $\Delta$ cells (Figure $3 A, B$ ). Most significantly, H3K9me2 was enriched at a 5 kilobase region covering $\mathrm{Clr}^{+}$and an adjacent gene meu6 ${ }^{+}$, at levels comparable to constitutive heterochromatin regions in independent clones tested (Figures $3 A, B$, and $4 A$, and data not shown). Consistent with the fact that $\mathrm{H} 3 \mathrm{~K} 9 \mathrm{me}$ is associated with gene silencing, both $\mathrm{clr} 4^{+} \mathrm{mRNA}$ and $\mathrm{Clr} 4$ protein levels were reduced in $m s t 2 \Delta$ epe $1 \Delta^{*}$ cells (Figure $4 B, C$ ).

To test if the epigenetically silenced clr $4^{+}$locus is the suppressor of mst2 $2 \Delta_{\text {epe }} 1 \Delta^{*}$ cells, we crossed mst2 2 epe $1 \Delta^{*}$ (containing a methylated clr $4^{+}$locus) with Flag-clr $4^{+}$cells (containing an unmethylated Flag-clr4 $4^{+}$locus). We found that the resulting mst $2 \Delta$ epe $1 \Delta \mathrm{clr} 4^{+}$daughters (inheriting the methylated

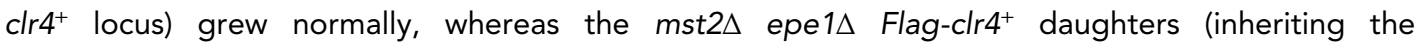
unmethylated Flag-clr4+ locus) were sick (Figure 4D). Moreover, ChIP analysis showed that the mst2 $\Delta$ epe $1 \Delta \mathrm{clr}^{+}$progeny also inherited $\mathrm{H} 3 \mathrm{~K} 9 \mathrm{me} 2$ associated with this locus (Figure $4 \mathrm{E}$ ), and $\mathrm{clr} 4^{+}$ mRNA levels were low (Figure 4F). Therefore, the inheritance of a silenced clr4 $4^{+}$locus allows cells to avoid the negative effects on cell growth imposed by mst2 $2 \Delta$ epe $1 \Delta$. In contrast, wild-type cells inheriting the methylated clr4 $4^{+}$locus lost $\mathrm{H} 3 \mathrm{~K} 9 \mathrm{me} 2, \mathrm{clr}^{+}$mRNA levels were significantly restored, and these cells exhibited no defects in the silencing of a pericentric otr:: ura $4^{+}$reporter gene (Figure $4 E, F$, G). These results suggest that the silencing of $\mathrm{clr}^{+}$is epigenetic and not due to changes in DNA sequence. They also suggest that the continued absence of Mst2 and Epe1 is required to maintain $\mathrm{H} 3 \mathrm{~K} 9 \mathrm{me} 2$ at the clr4+ locus. 
A

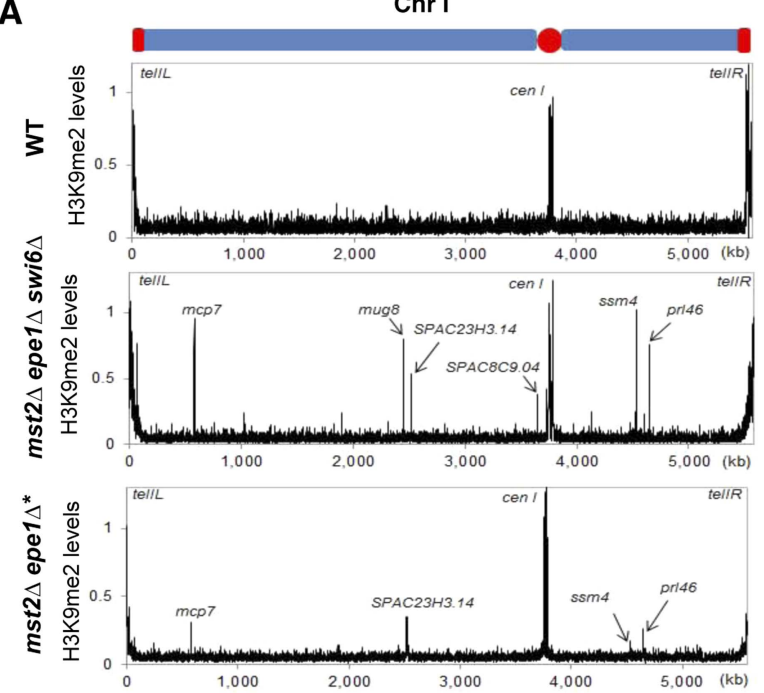

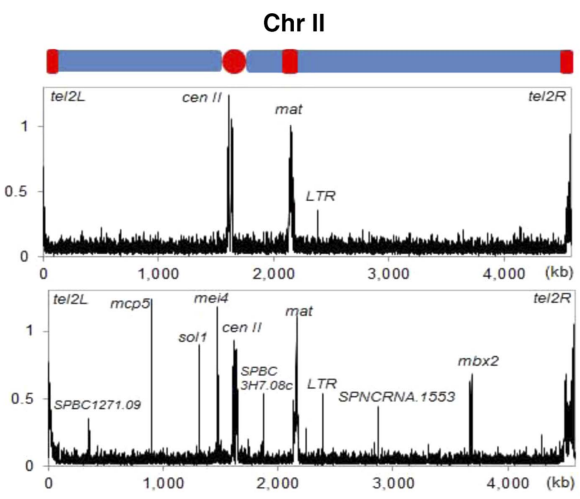

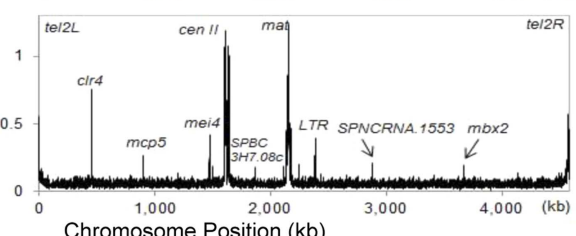

Chromosome Position (kb)
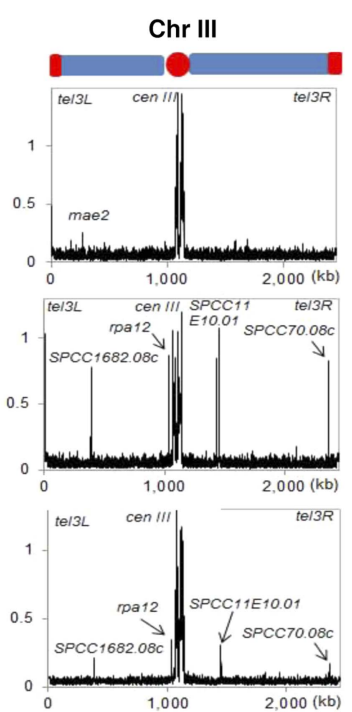

B
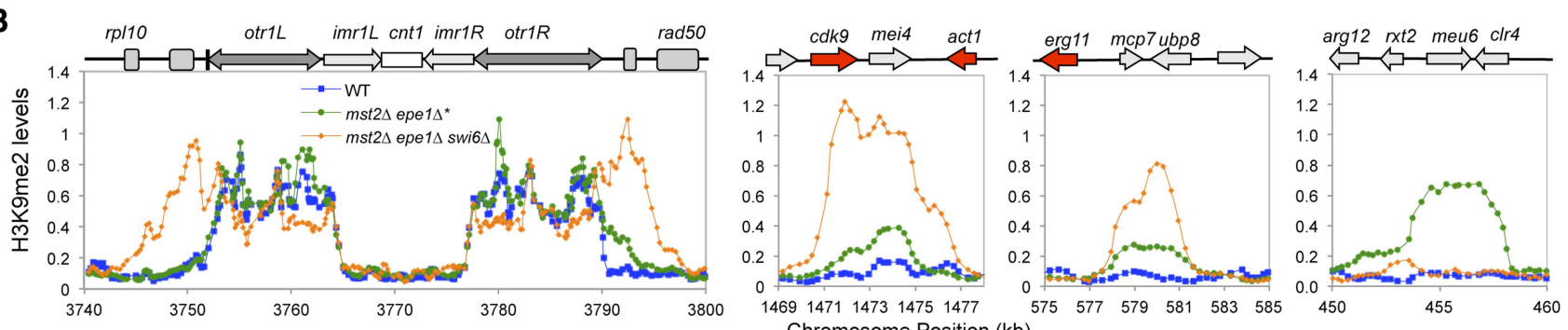

C

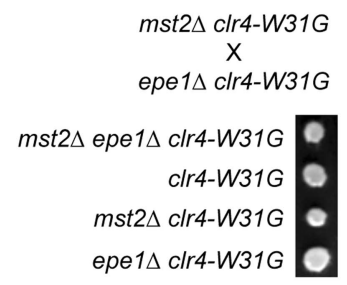

D Chromosome Position (kb)
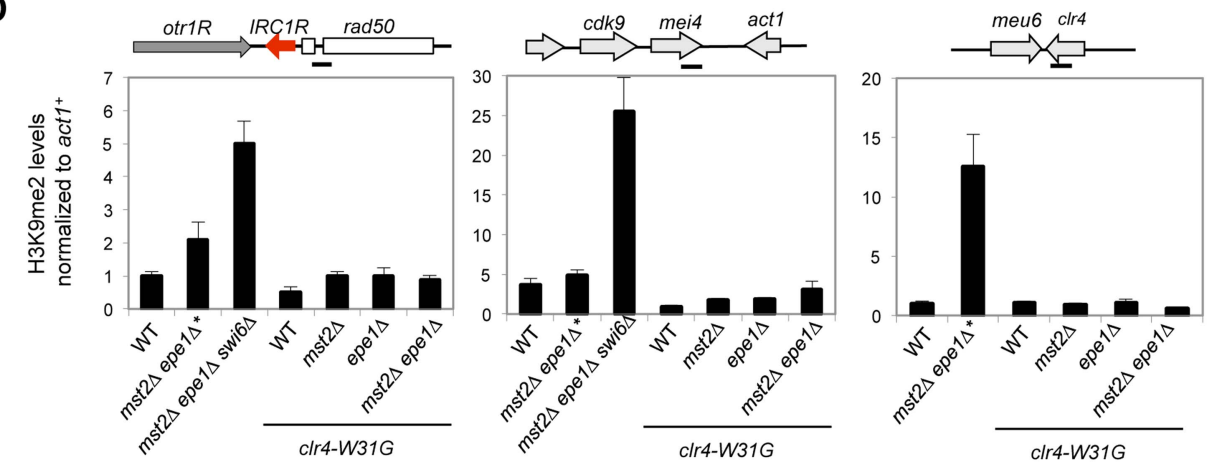

Figure 3. Increased heterochromatin spreading in mst2 $2 \Delta$ epe $1 \Delta$ cells leads to growth defects. (A) ChIP-chip analyses of H3K9me2 levels across the genome.

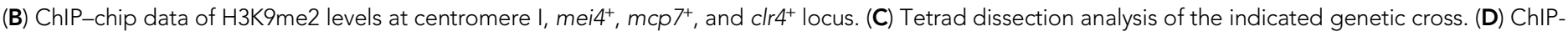
qPCR analysis of H3K9me2 levels at indicated locations, normalized against act $1^{+}$. Error bars represent standard deviation of three experiments. DOI: 10.7554/eLife.06179.008

The following figure supplement is available for figure 3 :

Figure supplement 1. ChIP-chip data of H3K9me2 levels at heterochromatin islands.

\section{Sequences $3^{\prime}$ to clr4 $4^{+}$is required for heterochromatin assembly at the clr4 $4^{+}$locus in mst2 $\Delta$ epe1 $1 \Delta$ cells}

We then examined whether any of the known heterochromatin assembly pathways are required for heterochromatin assembly at the $c / r 4^{+}$locus in mst $2 \Delta$ epe $1 \Delta$ cells. We found that mst $2 \Delta$ epe $1 \Delta$ dcr $1 \Delta$ cells also quickly recovered and $\mathrm{H} 3 \mathrm{~K} 9 \mathrm{me} 2$ levels were similar at the clr4 $4^{+}$locus in mst2 $\Delta_{\text {epe }} 1 \Delta^{*}$ and mst2 $\Delta$ epe $1 \Delta d c r 1 \Delta^{*}$ cells, suggesting that RNAi is not required for heterochromatin assembly at clr4 ${ }^{+}$, even though $\mathrm{clr}^{+}$is in a convergent orientation with meub (Figure 5-figure supplement 1). In 
A

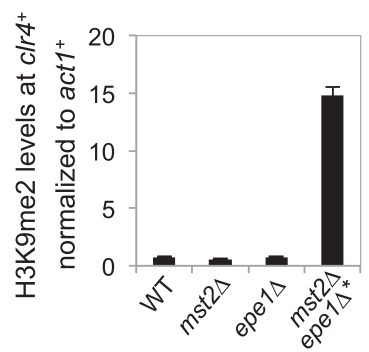

D
B

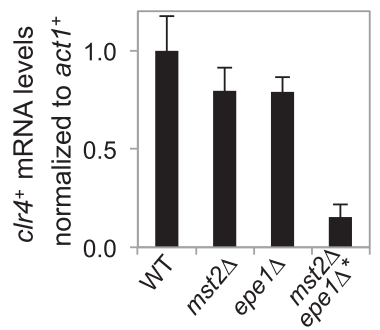

C

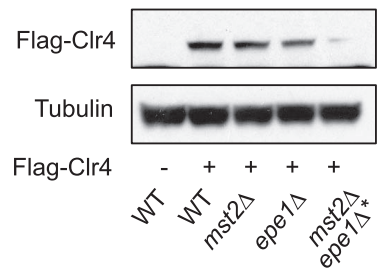

$m s t 2 \Delta$ epe $1 \Delta^{*} \mathrm{clr} 4^{+}$X Flag-clr4 ${ }^{+}$

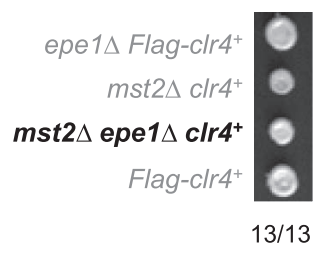

E

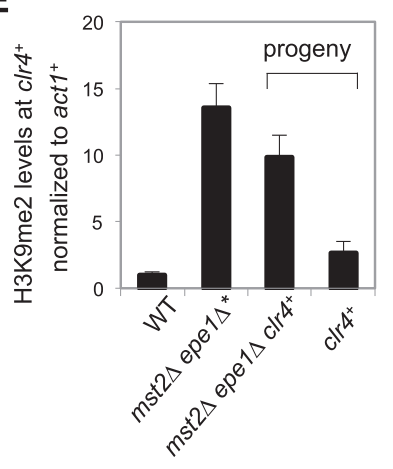

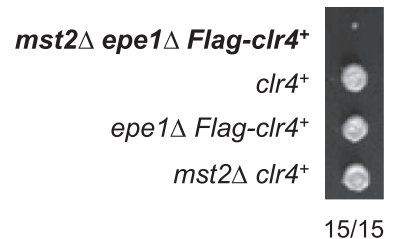

$\mathbf{F}$

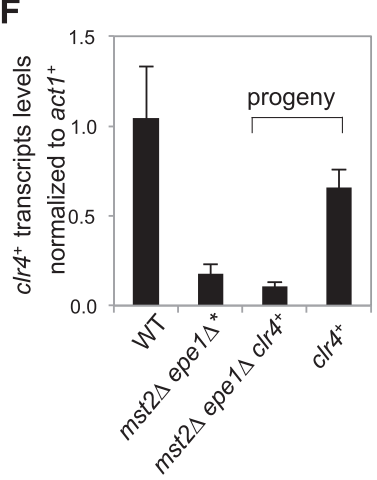

G

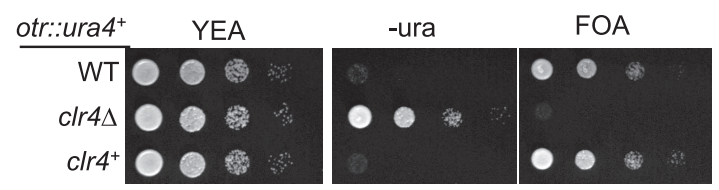

Figure 4. Inheritance of ectopic heterochromatin at the meu6-clr4 locus. (A, E) ChIP-qPCR analysis of H3K9me2 levels at the clr4 ${ }^{+}$coding region, normalized against act $1^{+}$. Error bars represent standard deviation of three experiments. (B, F) qRT-PCR analysis of clr4 ${ }^{+}$mRNA levels, normalized against act $1^{+}$. Error bars represent standard deviation of three experiments. (C) Western blot analyses of Flag-Clr4 and Tubulin protein levels. (D) Tetrad dissection analysis of indicated genetic crosses. (G) Serial dilution analysis to measure the expression of otr:: ura $^{+}$reporter. $^{2}$

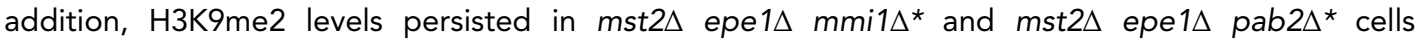
(Figure 5-figure supplement 1), suggesting that heterochromatin assembly is not through Mmi1-mediated facultative heterochromatin assembly pathway or Pab2-mediated assembly of HOOD, even though meu6 $6^{+}$is a meiotic gene. Therefore, heterochromatin assembly at clr $4^{+}$differs from known heterochromatin assembly pathways. Due to the severe growth defects associated with red $1 \Delta$ or $\operatorname{rrp} 6 \Delta$, we were unable to generate triple mutant strains with mst2 $\Delta$ epe $1 \Delta$ and whether these factors are involved in $\mathrm{H} 3 \mathrm{~K} 9 \mathrm{me} 2$ at the clr4 $4^{+}$locus in mst2 $2 \Delta$ epe $1 \Delta$ cells is unknown.

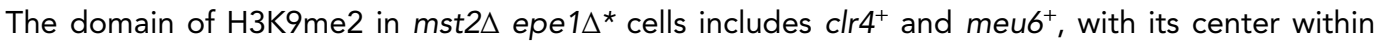
meu $6^{+}$coding region. Interestingly, RNA sequencing analysis showed that meu $6^{+}$is not expressed in vegetative growing cells and $\mathrm{clr} 4^{+}$transcript runs through the entire meu6 $6^{+}$gene (Figure 5A) (Wang et al., 2015). We therefore replaced the entire meub $6^{+}$open reading frame with a kanMX6 cassette, in the same transcription orientation as meu6 $6^{+}$(Figure 5B). Given that meub is right next to $\mathrm{clr}^{+}$, we first examined whether this manipulation affects Clr4 function. We found that meu6 $::$ kanMX6 has no silencing defects at otr::ura $4^{+}$, and $c 1 r 4^{+}$mRNA and Clr4 protein levels were similar to those of wild-type cells (Figure 5-figure supplement 2). ChIP analysis showed that $\mathrm{H} 3 \mathrm{~K} 9 \mathrm{me} 2$ was abolished at the $c l r 4^{+}$locus in mst2 $\Delta$ epe $1 \Delta$ meu6 $\Delta^{*}$ cells (Figure $5 \mathrm{C}$ ), and $c l r 4^{+}$mRNA and Clr4 protein levels 
A

A

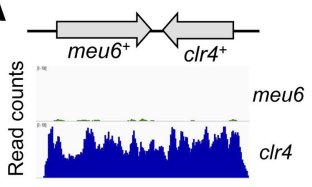

B

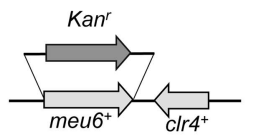

G

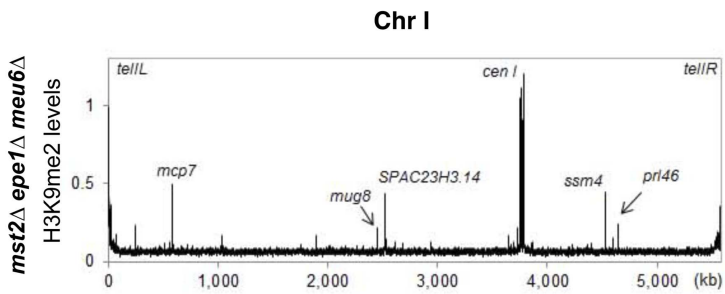

H

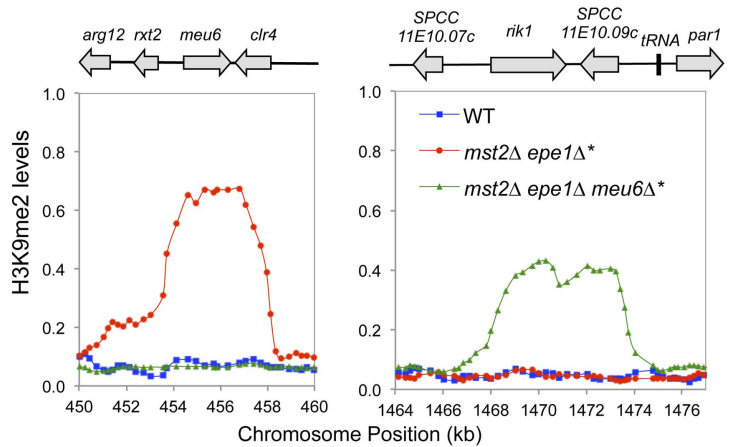

D

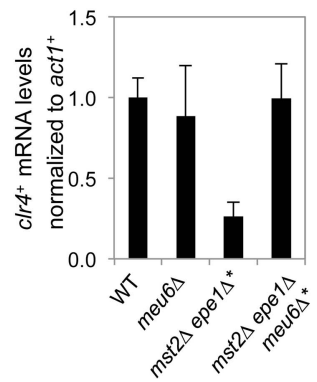

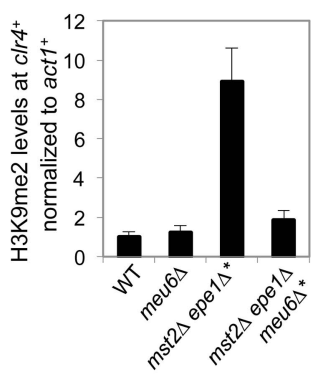

E

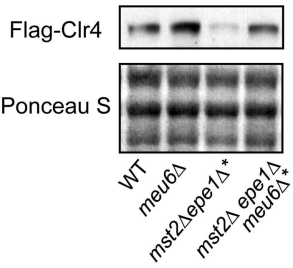

$\mathbf{F}$

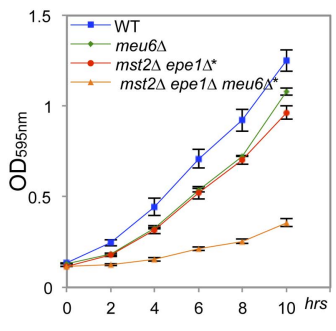

Chr II
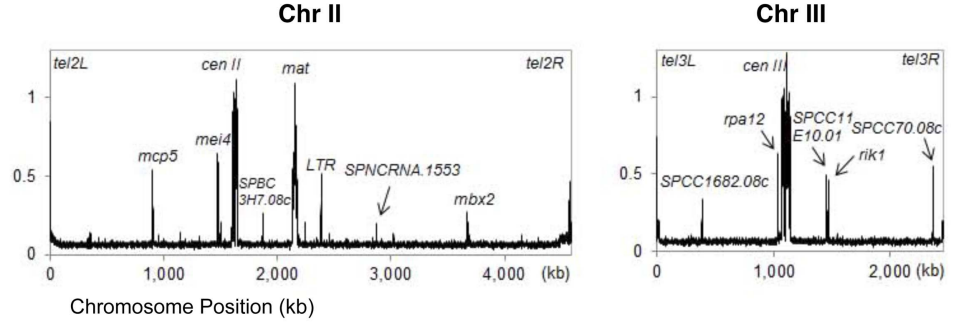

I
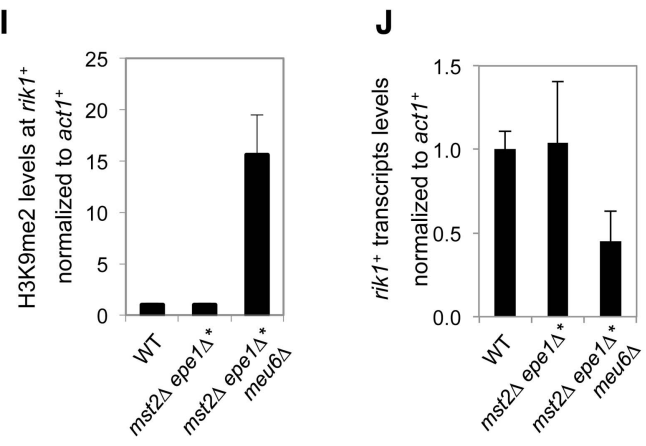

Figure 5. Blocking heterochromatin formation at the clr4+ locus in mst2 $\Delta$ epe $1 \Delta$ cells results in ectopic heterochromatin assembly at the rik $1^{+}$locus. (A) RNA sequencing data of the meu6-clr4 region. (B) Schematic diagram of the meu6 ::kanMX6 construct. (C, I) ChIP-qPCR analysis of H3K9me2 levels at the $c l r 4^{+}$or rik $1^{+}$coding region, normalized against act $1^{+}$. Error bars represent standard deviation of three experiments. (D, J) qRT-PCR analysis of clr $4^{+}$or rik $1^{+}$mRNA levels, normalized against act $1^{+}$. Error bars represent standard deviation of three experiments. (E) Western blot analyses of Flag-Clr4 protein levels. (F) The growth curve of indicated strains. (G) ChIP-chip analyses of H3K9me2 levels across the genome in recovered mst2 $\Delta$ epe1 $\Delta$ meu6 $\Delta^{\star}$ cells. (H) ChIP-chip data of H3K9me2 levels at clr4+ and rik1+ loci.

DOI: 10.7554 /eLife.06179.011

The following figure supplements are available for figure 5:

Figure supplement 1. Dcr1, Mmi1 and Pab2 are not required for heterochromatin assembly at the clr4 $4^{+}$locus in mst2 epe1 $\Delta^{*}$ cells. DOI: 10.7554/eLife.06179.012

Figure supplement 2. meu6 $\Delta$ has no effect on $c / r 4^{+}$expression under normal conditions.

DOI: 10.7554/eLife.06179.013

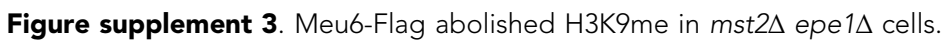

DOI: 10.7554/eLife.06179.014

were similar to wild-type cells (Figure 5D,E). We also generated a meu6-Flag::KanMX6 strain, which preserves the coding sequence of meu6 ${ }^{+}$, and found that $\mathrm{H} 3 \mathrm{~K} 9 \mathrm{me} 2$ levels at the $\mathrm{clr} 4^{+}$locus were also abolished in mst2 $2 \Delta$ epe1 $1 \Delta$ meu6-Flag::KanMX6 cells (Figure 5-figure supplement 3), suggesting that the meu $6^{+}$coding sequence is not responsible for heterochromatin assembly at this locus, but rather the insertion of the KanMX6 cassette disrupts a heterochromatin initiation signal. Given that the clr4 $4^{+}$transcript has a long $3^{\prime}$-UTR and that both meu64::KanMX6 and meu6-Flag::KanMX6 alter the $3^{\prime}-\mathrm{UTR}$, heterochromatin assembly at the clr4 $4^{+}$locus likely requires the intact $3^{\prime}-\mathrm{UTR}$ of $\mathrm{clr} 4^{+}$. 


\section{Disrupting ectopic heterochromatin assembly at the $\mathrm{clr4}^{+}$locus results in ectopic heterochromatin assembly at the rik $1^{+}$locus}

If the silenced $c l r 4^{+}$is the suppressor in mst2 $2 \Delta$ epe $1 \Delta^{*}$ cells, we expect that abolishing $\mathrm{H} 3 \mathrm{~K} 9 \mathrm{me} 2$ at the $c l r 4^{+}$locus will result in the failure of mst2 $2 \Delta$ epe $1 \Delta$ cells to recover. Interestingly, mst2 $\Delta$ epe $1 \Delta$ meu6 $\Delta^{*}$ cells were able to recover to some extent although they grew at a slower rate compared to wild-type or $m s t 2 \Delta$ epe $1 \Delta^{*}$ cells (Figure $5 F$ ). To understand how mst $2 \Delta$ epe $1 \Delta$ meu6 $\Delta^{*}$ cells recover

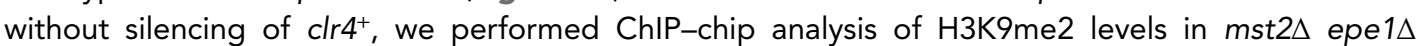
meu6 $\Delta^{*}$ cells (Figure $5 \mathrm{G}$ ). The distribution of H3K9me2 is on the whole similar to that of mst2 epe $1 \Delta^{*}$ cells, with two major exceptions. First, $\mathrm{H} 3 \mathrm{~K} 9 \mathrm{me} 2$ was indeed abolished from the entire meu6 ${ }^{+}$ -clr4+ region (Figure $5 \mathrm{G}, \mathrm{H}$ ). Second, an additional peak of H3K9me2 appeared at a 7-kb region that includes two genes in convergent orientation: rik $1^{+}$, which encodes a component of the $\mathrm{Clr} 4$ complex and is required for Clr4 function (Nakayama et al., 2001; Hong et al., 2005; Horn et al., 2005; Jia

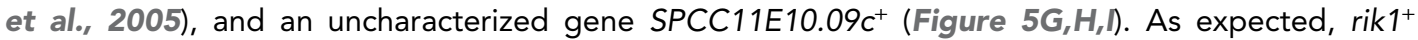
mRNA levels were significantly reduced in mst2 $2 \Delta$ epe $1 \Delta$ meu6 $6 \Delta^{*}$ cells compared to wild-type or mst2 $2 \Delta$ epe $1 \Delta^{*}$ cells (Figure $5 \mathrm{~J}$ ). It is likely that the reduction of rik $1^{+}$expression allows mst2 $\Delta$ epe $1 \Delta$ meu6 $\Delta^{*}$ cells to grow to some extent by decreasing global H3K9me and heterochromatin assembly. We suspect that mst2 $2 \Delta$ epe $1 \Delta$ meu6 $\Delta^{*}$ cells recovered less well than mst2 $2 \Delta$ epe $1 \Delta^{*}$ cells because heterochromatin forms less efficiently at the rik $1^{+}$locus, which might explain why independent mst2 $\Delta$ epe $1 \Delta^{*}$ clones all preferentially silenced $c l r 4^{+}$(data not shown). Moreover, H3K9me2 was also

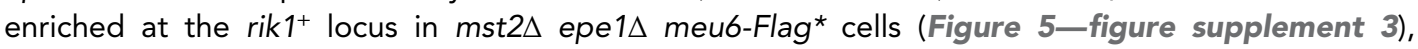
suggesting that the formation of heterochromatin at this locus is not random.

\section{Mst2 and Epe1 are required to counteract the high activity of Clr4}

It is interesting to note that the enzymatic activity of $\mathrm{Clr} 4$ is much higher than that of its mammalian counterparts (Rea et alo, 2000). Therefore, Mst2 and Epe1 are likely evolved to counteract such a hyperactive H3K9 methyltransferase. Clr4 has an arginine at residue 406, which corresponds to a histidine in its mammalian and Drosophila homologues (Figure 6A). Conversion of the histidine to arginine (H320R) makes mammalian SUV39H1 a hyperactive histone methyltransferase (Rea et al., 2000). We generated a $\mathrm{R} 406 \mathrm{H}$ mutation in $\mathrm{Clr} 4$ and found that this mutation resulted in a drastic reduction of $\mathrm{Clr} 4$ enzymatic activity in vitro (Figure 6B). When introduced into the endogenous $\mathrm{Clr}^{+}$ locus, $\mathrm{R} 406 \mathrm{H}$ moderately affected silencing of a pericentric otr::ura $4^{+}$reporter, indicating that high activity of $\mathrm{Clr} 4$ is required for heterochromatin assembly in wild-type cells (Figure 6-figure supplement 1). Interestingly, mst2 $\Delta$ epe $1 \Delta \mathrm{clr} 4-\mathrm{R} 406 \mathrm{H}$ had no initial growth defects (Figure 6C), no $\mathrm{H} 3 \mathrm{~K} 9 \mathrm{me} 2$ at the $\mathrm{clr} 4^{+}$locus (Figure 6D), and clr4 $4^{+}$transcript levels were not affected (Figure 6E). Therefore, a less active Clr4 can also mitigate the effects of simultaneous loss of Mst2 and Epe1.

\section{Discussion}

The formation of heterochromatin and its subsequent spreading result in silencing of large chromosomal domains in a sequence-independent manner. Therefore, the sites of heterochromatin assembly and the extent of heterochromatin spreading are generally precisely controlled to maintain stable gene expression patterns. In addition to the diverse pathways that accurately initiate heterochromatin assembly, anti-silencing activities also play essential roles in limiting heterochromatin spreading to shape the chromatin landscape.

Our results reveal a novel function of the Mst2 complex in regulating histone turnover at heterochromatin regions to counteract heterochromatin spreading. Loss of Mst2 bypasses the requirement of RNAi for pericentric heterochromatin assembly (Reddy et al., 2011), increases heterochromatin spreading and silencing at telomeres (Figure 1) (Gomez et al., 2005), and increases the efficiency of ectopic heterochromatin assembly (Ragunathan et al., 2014), which is phenotypically very similar to epe1A. Biochemically, the Mst2 complex is a highly specific histone H3K14 acetyltransferase and mutations resulting in the loss of its enzymatic activity, such as mst2-E274O or nto1 1 (Wang et al., 2012), also resulted in slow growth when combined with epe1 $\Delta$, suggesting that its enzymatic activity is required for counteracting silencing. $H 3 K 14$ mutants have a direct effect on heterochromatin assembly independent of its acetylation state, making it difficult to directly address whether H3K14 is the only target of Mst2 in regulating heterochromatin spreading (Mellone et al., 2003; Reddy et al., 2011; Alper et al., 2013). Therefore, it remains possible that Mst2 modifies heterochromatin assembly factors to regulate histone turnover and counteract silencing. 
A

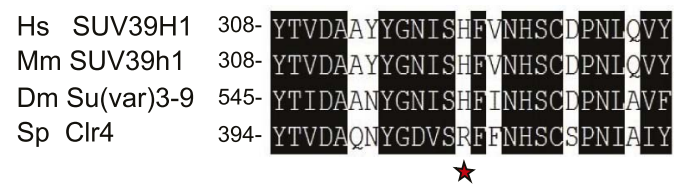

D

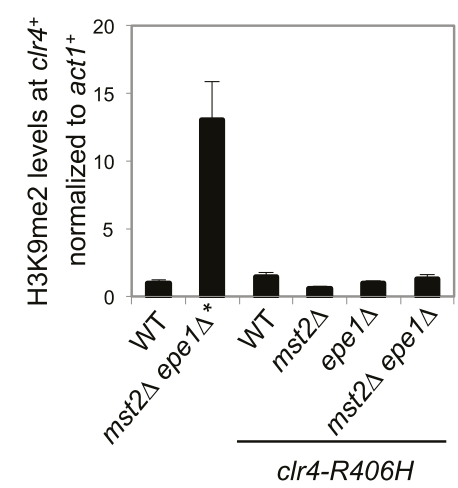

E
B

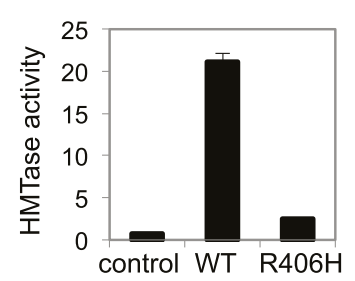

C

$m s t 2 \Delta$ clr4R406H X epe1 $\mathrm{clr} 4 \mathrm{R} 406 \mathrm{H}$

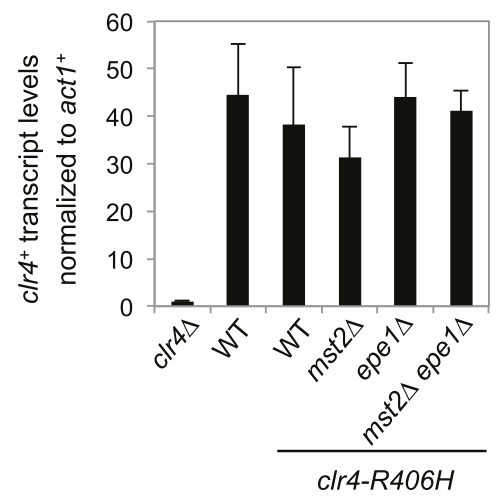

Figure 6. The high activity of $\mathrm{Clr} 4$ leads to growth defects of mst2 $\Delta$ epe $1 \Delta$ cells. (A) Sequence alignment of part of Clr4 homologues. * indicates R406 of Clr4. (B) In vitro histone methyltransferase assays were performed with recombinant GST-Clr4 or GST-Clr4-R406H together with a histone H3 (1-21) peptide. For the control reaction, no Clr4 was added. (C) Tetrad dissection analysis of the indicated genetic cross. (D) ChIP-qPCR analysis of H3K9me2 levels at the $c l r 4^{+}$coding region, normalized against act $1^{+}$. Error bars represent standard deviation of three experiments. (E) qRT-PCR analysis of clr4 ${ }^{+}$ mRNA levels, normalized against act $1^{+}$. Error bars represent standard deviation of three experiments.

DOI: 10.7554/eLife.06179.015

The following figure supplement is available for figure 6:

Figure supplement 1. The effect of clr4- $\mathrm{R} 406 \mathrm{H}$ on silencing of otr:: $u r a 4^{+}$.

Our results also revealed the functional redundancy of Mst2 and Epe1 in regulating heterochromatin spreading, which explains why heterochromatin spreading only occurs in a small population of cells and requires the overexpression of Swi6 to be efficiently detected (Noma et al., 2006; Wang et al., 2013). In the absence of both Mst2 and Epe1, heterochromatin spreading increases significantly, leading to the inactivation of essential genes and severe growth defects. Such strong survival pressure results in the selection of cells that can establish heterochromatin at the $c / r 4^{+}$ locus, leading to reduced transcription of $\mathrm{clr}^{+}{ }^{+}$and decreased $\mathrm{Clr} 4$ protein levels, thus allowing cells to reach a new equilibrium where heterochromatin assembly at regular locations is intact while the negative effects of heterochromatin spreading are mitigated (Figure 7 ). Although we cannot test the epigenetic profiles of individual cells, it is possible that mst2s epe1s cells initially generate varied epigenetic profiles, and only cells containing H3K9me at the meu6-clr4 locus are clonally selected due to its beneficial effects on cell growth. The quick generation of this epigenetic suppressor also benefited from the stabilization of ectopic heterochromatin domains in mst2 $\Delta$ epe $1 \Delta$ cells. Once established, such ectopic heterochromatin can be inherited, but can also be quickly erased to allow cells to adapt to new conditions. Interestingly, when $\mathrm{H} 3 \mathrm{~K} 9 \mathrm{me}$ at the $\mathrm{clr} 4^{+}$locus is blocked, the survival pressure instead selects cells that can establish heterochromatin at the rik $1^{+}$locus to similarly reduce heterochromatin-forming abilities. The flexibility in heterochromatin assembly allows cells and their subsequent generations to efficiently cope with changes in heterochromatin levels.

The formation of heterochromatin at the $\mathrm{clr} 4^{+}$locus does not employ any of the known heterochromatin assembly pathways. The intact $3^{\prime}$-UTR region of $\mathrm{clr}^{+}$seems to initiate heterochromatin through a novel mechanism, although such a mechanism must be very inefficient in wild-type cells given that no $\mathrm{H} 3 \mathrm{~K} 9 \mathrm{me}$ is observed. It is interesting to note that the $3^{\prime}-\mathrm{UTR}$ of $c / r 4^{+}$ 

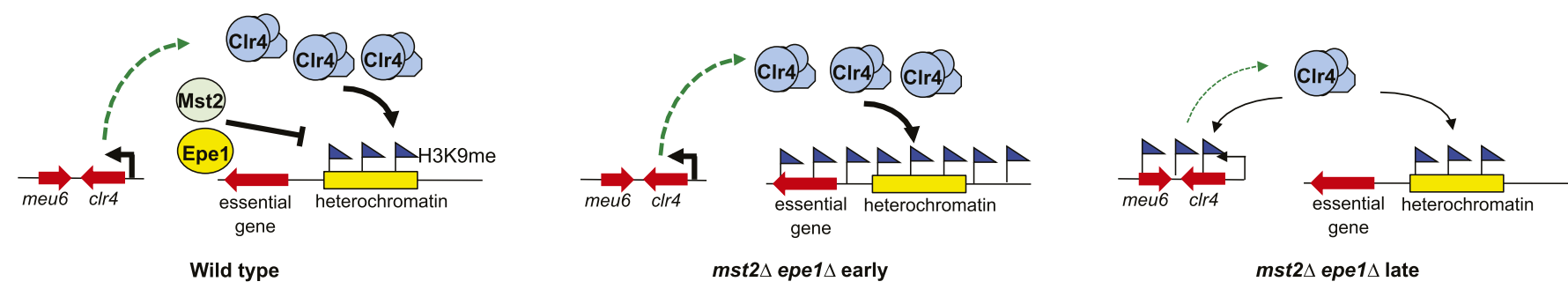

Figure 7. A model of the negative feedback of heterochromatin assembly. DOI: 10.7554/eLife.06179.017

overlaps the entire meub $6^{+}$gene, which is arranged in a convergent orientation. The expression of meu6 $6^{+}$is extremely low during vegetative growth, but is upregulated during meiosis, which might interfere with Clr4 expression, resulting in the loss of heterochromatin islands as seen in cells under conditions that induce meiosis (Zofall et al., 2012).

It has long been known that heterochromatin assembly in fission yeast is tightly regulated to prevent promiscuous heterochromatin assembly. For example, the amount of heterochromatin proteins such as Swib is limiting, and ectopic heterochromatin assembly can only succeed when Swib is overexpressed or when endogenous heterochromatin structures are compromised to release silencing proteins (lida et al., 2008; Kagansky et al., 2009; Tadeo et al., 2013). Moreover, subtelomeric heterochromatin regions, which contain no boundaries and no essential genes, can serve as 'sinks' to absorb extra heterochromatin proteins (Tadeo et al., 2013). These extensive pathways that limit heterochromatin assembly might be a response to the high enzymatic activity of $\mathrm{Clr4}$, which is likely required for heterochromatin assembly in an otherwise highly compact and active genome. Our results provide an additional layer of control for cells to monitor heterochromatin levels through a negative feedback mechanism that uses the potentially promiscuous nature of heterochromatin assembly to induce heterochromatin formation at genes encoding heterochromatin assembly factors, thus ensuring the epigenetic stability of the genome.

Our results fit into a growing body of evidence demonstrating that epigenetic regulation of gene expression enables cells to adopt a wide variety of phenotypes to adapt to external or internal stresses (Heard and Martienssen, 2014). Compared to genetic mutations, epigenetic mutations provide much faster responses. Most importantly, the effects are reversible, allowing easy reversion to normal epigenetic profiles when external stimuli disappear. In cancer cells, such epigenetic variations might result in the inactivation of tumor suppressor genes during tumorigenesis and might also enable tumor cells to survive certain therapies (Sharma et al., 2010; Kreso et al., 2013). Therefore, our work sheds light on the mechanisms underlying how a relatively stable heterochromatic profile is maintained both under normal conditions and upon heterochromatin stress and will guide future efforts to combat epigenetic adaptations that interfere with cancer treatment.

\section{Materials and methods}

\section{Fission yeast strains and genetic analyses}

Detailed genotypes of strains used are listed in Supplementary file 3. Strains containing meu6s or meu6-Flag and urg1-hht2-Flag were constructed by a PCR-based module method. Genetic crosses were used to construct all other strains. For serial dilution plating assays, ten-fold dilutions of mid-logphase cultures were plated on the indicated medium and grown for 3 days at $30^{\circ} \mathrm{C}$.

\section{Genetic screen of the fission yeast deletion library}

A two-step cross scheme was employed to avoid the accumulation of suppressors before colony growth measurement. Query strains (mst2A::natMX6 and epe1 $\Delta:: h p h M X 6$ ) were first separately mated with the fission yeast deletion library arrayed in 384 strains/plate format with the aid of the Singer RoToR HDA pinning robot as previously described (Tadeo et al., 2013). After mating and 
selection, the resulting haploid double mutant libraries containing individual gene deletions with either $m s t 2 \Delta$ or epe $1 \Delta$ were mated again, and haploid triple mutants were selected on YES medium supplemented with antibiotics to measure cell growth.

\section{Chromatin immunoprecipitation (ChIP) analysis}

ChIP analyses with H3K9me2 antibody (Abcam, Cambridge, MA) were performed as described previously (Tadeo et al., 2013). Quantitative real-time PCR (qPCR) was performed with Maxima SYBR Green qPCR Master Mix (Fermentas, Grand Island, NY) in a StepOne Plus Real-Time PCR System (Applied Biosystems, Grand Island, NY). DNA serial dilutions were used as templates to generate a standard curve of amplification for each pair of primers, and the relative concentration of the target sequence was calculated accordingly. An act1 fragment was used as reference to calculate the enrichment of ChIP over WCE for each target sequence. Oligos used are listed in Supplementary file 4.

For histone turnover assay, cells were cultured in EMM-uracil medium, and then arrested for $4 \mathrm{hr}$ by $20 \mathrm{~mm} \mathrm{HU}$, followed by the addition of $0.25 \mathrm{mg} / \mathrm{ml}$ uracil to induce the expression of H3-Flag, before ChIP analysis was performed.

ChIP-chip analyses were performed according to the 'Agilent Yeast ChIP-on-chip Analysis' protocol. The microarray used was an Agilent S. pombe Whole Genome ChIP-on-chip Microarray with additional probes that encompass centromeres, which were originally absent from the array due to the repetitive nature of these DNA sequences. At least two repeats were performed for each microarray experiment. To control for the experimental variation, the average of top 20 probes was set to 1 before averaging the results. For heterochromatin islands, the cutoff of $\mathrm{H} 3 \mathrm{~K} 9 \mathrm{me} 2$ levels is 0.2 . Microarray data have been deposited in the GEO database under accession number GSE60521.

\section{RNA analyses}

Total cellular RNA was isolated from log-phase cells using MasterPure yeast RNA purification kit (Epicentre, Madison, WI) according to the manufacturer's protocol. Quantification with qRT-PCR was performed with Power SYBR Green RNA-to-CT one-step Kit (Applied Biosystems). RNA serial dilutions were used as templates to generate the standard curve of amplification for each pair of primers, and the relative concentration of target sequence was calculated accordingly. An act1 fragment served as reference to normalize the concentration of samples. The concentration of each target gene in wild type was arbitrarily set to 1 and served as references for other samples. Oligos used are listed in Supplementary file 4.

\section{Acknowledgements}

We thank Xavier Tadeo for help with SGA screen, Anudari Letian for technical assistance, James Manley, Hengbin Wang, and members of the Jia lab for helpful discussions and critical reading of the manuscript. This work was supported by National Institutes of Health grants R01-GM085145 to SJ. BDR was supported by $\mathrm{NIH}$ training grant T32-GM008798.

\section{Additional information}

Funding

\begin{tabular}{lll} 
Funder & Grant reference & Author \\
\hline National Institutes of Health $(\mathrm{NIH})$ & R01-GM085145 & Songtao Jia \\
\hline National Institutes of Health (NIH) & T32-GM008798 & Bharat D Reddy \\
\hline
\end{tabular}

The funder had no role in study design, data collection and interpretation, or the decision to submit the work for publication.

Author contributions

JW, BDR, Conception and design, Acquisition of data, Analysis and interpretation of data; SJ, Conception and design, Acquisition of data, Analysis and interpretation of data, Drafting or revising the article 


\section{Additional files}

Supplementary files

- Supplementary file 1. List of heterochromatin peaks in different genetic background.

DOI: 10.7554/eLife.06179.018

- Supplementary file 2. List of mutations identified in SGA screen.

DOI: 10.7554/eLife.06179.019

- Supplementary file 3. Yeast strains used in this study.

DOI: 10.7554/eLife.06179.020

- Supplementary file 4. Primers used in this study.

DOI: $10.7554 /$ eLife.06179.021

Major dataset

The following dataset was generated:

\begin{tabular}{lllll}
\hline $\begin{array}{l}\text { Author } \\
\text { (s) }\end{array}$ & Year & Dataset title & $\begin{array}{l}\text { Dataset ID } \\
\text { and/or URL }\end{array}$ & $\begin{array}{l}\text { Database, license, and } \\
\text { accessibility information }\end{array}$ \\
\hline Wang J $2014 \begin{array}{l}\text { Epigenetic adaptation to } \\
\text { uncontrolled heterochromatin } \\
\text { spreading }\end{array}$ & $\begin{array}{l}\text { http://www.ncbi.nlm.nih.gov/ } \\
\text { geo/query/acc.cgi? } \\
\text { acc=GSE60521 }\end{array}$ & $\begin{array}{l}\text { Publicly available at NCBI Gene } \\
\text { Expression Omnibus }\end{array}$ \\
& & (GSE60521).
\end{tabular}

\section{References}

Al-Sady B, Madhani HD, Narlikar GJ. 2013. Division of labor between the chromodomains of HP1 and Suv39 methylase enables coordination of heterochromatin spread. Molecular Cell 51:80-91. doi: 10.1016/j.molcel. 2013.06.013.

Alper BJ, Job G, Yadav RK, Shanker S, Lowe BR, Partridge JF. 2013. Sir2 is required for Clr4 to initiate centromeric heterochromatin assembly in fission yeast. The EMBO Journal 32:2321-2335. doi: 10.1038/ emboj.2013.143.

Aygun O, Mehta S, Grewal SI. 2013. HDAC-mediated suppression of histone turnover promotes epigenetic stability of heterochromatin. Nature Structural \& Molecular Biology 20:547-554.

Bannister AJ, Zegerman P, Partridge JF, Miska EA, Thomas JO, Allshire RC, Kouzarides T. 2001. Selective recognition of methylated lysine 9 on histone H3 by the HP1 chromo domain. Nature 410:120-124. doi: 10.1038/ 35065138.

Cam HP, Sugiyama T, Chen ES, Chen X, FitzGerald PC, Grewal SI. 2005. Comprehensive analysis of heterochromatin- and RNAi-mediated epigenetic control of the fission yeast genome. Nature Genetics 37: 809-819. doi: 10.1038/ng1602.

Castel SE, Martienssen RA. 2013. RNA interference in the nucleus: roles for small RNAs in transcription, epigenetics and beyond. Nature Reviews Genetics 14:100-112. doi: 10.1038/nrg3355.

Cohen A, Jia S. 2014. Noncoding RNAs and the borders of heterochromatin. Wiley Interdisciplinary Reviews RNA 5: 835-847. doi: 10.1002/wrna.1249.

Egan ED, Braun CR, Gygi SP, Moazed D. 2014. Post-transcriptional regulation of meiotic genes by a nuclear RNA silencing complex. RNA 20:867-881. doi: 10.1261/rna.044479.114.

Geutjes EJ, Bajpe PK, Bernards R. 2012. Targeting the epigenome for treatment of cancer. Oncogene 31: 3827-3844. doi: 10.1038/onc.2011.552.

Gomez EB, Espinosa JM, Forsburg SL. 2005. Schizosaccharomyces pombe mst2+ encodes a MYST family histone acetyltransferase that negatively regulates telomere silencing. Molecular and Cellular Biology 25:8887-8903. doi: 10.1128/MCB.25.20.8887-8903.2005.

Grewal SI, Jia S. 2007. Heterochromatin revisited. Nature Reviews Genetics 8:35-46. doi: 10.1038/nrg2008.

Grewal SI, Moazed D. 2003. Heterochromatin and epigenetic control of gene expression. Science 301:798-802. doi: $10.1126 /$ science.1086887.

Gullerova M, Proudfoot NJ. 2008. Cohesin complex promotes transcriptional termination between convergent genes in S. pombe. Cell 132:983-995. doi: 10.1016/j.cell.2008.02.040.

Hall IM, Shankaranarayana GD, Noma K, Ayoub N, Cohen A, Grewal SI. 2002. Establishment and maintenance of a heterochromatin domain. Science 297:2232-2237. doi: 10.1126/science.1076466.

Harigaya Y, Tanaka H, Yamanaka S, Tanaka K, Watanabe Y, Tsutsumi C, Chikashige Y, Hiraoka Y, Yamashita A, Yamamoto M. 2006. Selective elimination of messenger RNA prevents an incidence of untimely meiosis. Nature 442:45-50. doi: 10.1038/nature04881.

Heard E, Martienssen RA. 2014. Transgenerational epigenetic inheritance: myths and mechanisms. Cell 157: 95-109. doi: 10.1016/j.cell.2014.02.045.

Hiriart E, Vavasseur A, Touat-Todeschini L, Yamashita A, Gilquin B, Lambert E, Perot J, Shichino Y, Nazaret N, Boyault C, Lachuer J, Perazza D, Yamamoto M, Verdel A. 2012. Mmi1 RNA surveillance machinery directs RNAi complex RITS to specific meiotic genes in fission yeast. The EMBO Journal 31:2296-2308. doi: 10.1038/emboj. 2012.105 . 
Hong EJ, Villen J, Gerace EL, Gygi SP, Moazed D. 2005. A cullin E3 ubiquitin ligase complex associates with Rik1 and the $\mathrm{Clr} 4$ histone $\mathrm{H} 3-\mathrm{K} 9$ methyltransferase and is required for RNAi-mediated heterochromatin formation. RNA Biology 2:106-111. doi: 10.4161/rna.2.3.2131.

Horn PJ, Bastie JN, Peterson CL. 2005. A Rik1-associated, cullin-dependent E3 ubiquitin ligase is essential for heterochromatin formation. Genes \& Development 19:1705-1714. doi: 10.1101/gad.1328005.

lida T, Nakayama J, Moazed D. 2008. siRNA-mediated heterochromatin establishment requires HP1 and is associated with antisense transcription. Molecular Cell 31:178-189. doi: 10.1016/j.molcel.2008.07.003.

Jia S, Kobayashi R, Grewal SI. 2005. Ubiquitin ligase component Cul4 associates with Clr4 histone methyltransferase to assemble heterochromatin. Nature Cell Biology 7:1007-1013. doi: 10.1038/ncb1300.

Jia S, Noma K, Grewal SI. 2004. RNAi-independent heterochromatin nucleation by the stress-activated ATF/CREB family proteins. Science 304:1971-1976. doi: 10.1126/science.1099035.

Kagansky A, Folco HD, Almeida R, Pidoux AL, Boukaba A, Simmer F, Urano T, Hamilton GL, Allshire RC. 2009. Synthetic heterochromatin bypasses RNAi and centromeric repeats to establish functional centromeres. Science 324:1716-1719. doi: 10.1126/science.1172026.

Kanoh J, Sadaie M, Urano T, Ishikawa F. 2005. Telomere binding protein Taz1 establishes Swi6 heterochromatin independently of RNAi at telomeres. Current Biology 15:1808-1819. doi: 10.1016/j.cub.2005.09.041.

Kim HS, Choi ES, Shin JA, Jang YK, Park SD. 2004. Regulation of Swi6/HP1-dependent heterochromatin assembly by cooperation of components of the mitogen-activated protein kinase pathway and a histone deacetylase Clr6. The Journal of Biological Chemistry 279:42850-42859. doi: 10.1074/jbc.M407259200.

Kreso A, O'Brien CA, van Galen P, Gan OI, Notta F, Brown AM, Ng K, Ma J, Wienholds E, Dunant C, Pollett A, Gallinger S, McPherson J, Mullighan CG, Shibata D, Dick JE. 2013. Variable clonal repopulation dynamics influence chemotherapy response in colorectal cancer. Science 339:543-548. doi: 10.1126/science.1227670.

Lachner M, O'Carroll D, Rea S, Mechtler K, Jenuwein T. 2001. Methylation of histone H3 lysine 9 creates a binding site for HP1 proteins. Nature 410:116-120. doi: 10.1038/35065132.

Lee NN, Chalamcharla VR, Reyes-Turcu F, Mehta S, Zofall M, Balachandran V, Dhakshnamoorthy J, Taneja N, Yamanaka S, Zhou M, Grewal SI. 2013. Mtr4-like protein coordinates nuclear RNA processing for

heterochromatin assembly and for telomere maintenance. Cell 155:1061-1074. doi: 10.1016/j.cell.2013.10.027.

Lejeune E, Allshire RC. 2011. Common ground: small RNA programming and chromatin modifications. Current Opinion in Cell Biology 23:258-265. doi: 10.1016/j.ceb.2011.03.005.

Mellone BG, Ball L, Suka N, Grunstein MR, Partridge JF, Allshire RC. 2003. Centromere silencing and function in fission yeast is governed by the amino terminus of histone H3. Current Biology 13:1748-1757. doi: 10.1016/j.cub. 2003.09.031.

Moazed D. 2009. Small RNAs in transcriptional gene silencing and genome defence. Nature 457:413-420. doi: 10. 1038/nature07756.

Moazed D. 2011. Mechanisms for the inheritance of chromatin states. Cell 146:510-518. doi: 10.1016/j.cell.2011. 07.013.

Motamedi MR, Hong EJ, Li X, Gerber S, Denison C, Gygi S, Moazed D. 2008. HP1 proteins form distinct complexes and mediate heterochromatic gene silencing by nonoverlapping mechanisms. Molecular Cell 32 778-790. doi: 10.1016/j.molcel.2008.10.026.

Nakayama J, Rice JC, Strahl BD, Allis CD, Grewal SI. 2001. Role of histone H3 lysine 9 methylation in epigenetic control of heterochromatin assembly. Science 292:110-113. doi: 10.1126/science.1060118.

Noma K, Cam HP, Maraia RJ, Grewal SI. 2006. A role for TFIIIC transcription factor complex in genome organization. Cell 125:859-872. doi: 10.1016/j.cell.2006.04.028.

Nugent RL, Johnsson A, Fleharty B, Gogol M, Xue-Franzen Y, Seidel C, Wright AP, Forsburg SL. 2010. Expression profiling of $\mathrm{S}$. pombe acetyltransferase mutants identifies redundant pathways of gene regulation. $B M C$ Genomics 11:59. doi: 10.1186/1471-2164-11-59.

Ragunathan K, Jih G, Moazed D. 2014. Epigenetics. Epigenetic inheritance uncoupled from sequence-specific recruitment. Science 348:1258699. doi: 10.1126/science.1258699.

Rea S, Eisenhaber F, O'Carroll D, Strahl BD, Sun ZW, Schmid M, Opravil S, Mechtler K, Ponting CP, Allis CD, Jenuwein T. 2000. Regulation of chromatin structure by site-specific histone H3 methyltransferases. Nature 406: 593-599. doi: 10.1038/35020506.

Reddy BD, Wang Y, Niu L, Higuchi EC, Marguerat SB, Bahler J, Smith GR, Jia S. 2011. Elimination of a specific histone H3K14 acetyltransferase complex bypasses the RNAi pathway to regulate pericentric heterochromatin functions. Genes \& Development 25:214-219. doi: 10.1101/gad.1993611.

Roguev A, Bandyopadhyay S, Zofall M, Zhang K, Fischer T, Collins SR, Qu H, Shales M, Park HO, Hayles J, Hoe KL, Kim DU, Ideker T, Grewal SI, Weissman JS, Krogan NJ. 2008. Conservation and rewiring of functional modules revealed by an epistasis map in fission yeast. Science 322:405-410. doi: 10.1126/science.1162609.

Rusche LN, Kirchmaier AL, Rine J. 2003. The establishment, inheritance, and function of silenced chromatin in Saccharomyces cerevisiae. Annual Review of Biochemistry 72:481-516. doi: 10.1146/annurev.biochem.72. 121801.161547.

Ryan CJ, Roguev A, Patrick K, Xu J, Jahari H, Tong Z, Beltrao P, Shales M, Qu H, Collins SR, Kliegman Jl, Jiang L, Kuo D, Tosti E, Kim HS, Edelmann W, Keogh MC, Greene D, Tang C, Cunningham P, Shokat KM, Cagney G, Svensson JP, Guthrie C, Espenshade PJ, Ideker T, Krogan NJ. 2012. Hierarchical modularity and the evolution of genetic interactomes across species. Molecular Cell 46:691-704. doi: 10.1016/j.molcel.2012.05.028.

Sharma SV, Lee DY, Li B, Quinlan MP, Takahashi F, Maheswaran S, McDermott U, Azizian N, Zou L, Fischbach MA, Wong KK, Brandstetter K, Wittner B, Ramaswamy S, Classon M, Settleman J. 2010. A chromatin-mediated reversible drug-tolerant state in cancer cell subpopulations. Cell 141:69-80. doi: 10.1016/j.cell.2010.02.027. 
Sugiyama T, Cam HP, Sugiyama R, Noma K, Zofall M, Kobayashi R, Grewal SI. 2007. SHREC, an effector complex for heterochromatic transcriptional silencing. Cell 128:491-504. doi: 10.1016/j.cell.2006.12.035.

Tadeo X, Wang J, Kallgren SP, Liu J, Reddy BD, Qiao F, Jia S. 2013. Elimination of shelterin components bypasses RNAi for pericentric heterochromatin assembly. Genes \& Development 27:2489-2499. doi: 10.1101/gad.226118.113.

Talbert PB, Henikoff S. 2006. Spreading of silent chromatin: inaction at a distance. Nature Reviews Genetics 7: 793-803. doi: 10.1038/nrg1920.

Tashiro S, Asano T, Kanoh J, Ishikawa F. 2013. Transcription-induced chromatin association of RNA surveillance factors mediates facultative heterochromatin formation in fission yeast. Genes To Cells 18:327-339. doi: 10 1111/gtc. 12038.

Trewick SC, Minc E, Antonelli R, Urano T, Allshire RC. 2007. The JmjC domain protein Epe1 prevents unregulated assembly and disassembly of heterochromatin. The EMBO Journal 26:4670-4682. doi: 10.1038/sj.emboj. 7601892.

Tsukada Y, Fang J, Erdjument-Bromage H, Warren ME, Borchers CH, Tempst P, Zhang Y. 2006. Histone demethylation by a family of JmjC domain-containing proteins. Nature 439:811-816. doi: 10.1038/nature04433.

Wang J, Lawry ST, Cohen AL, Jia S. 2014. Chromosome boundary elements and regulation of heterochromatin spreading. Cellular and Molecular Life Sciences 71:4841-4852. doi: 10.1007/s00018-014-1725-x.

Wang J, Tadeo X, Hou H, Andrews S, Moresco JJ, Yates JR III, Nagy PL, Jia S. 2015. Tls1 regulates splicing of shelterin components to control telomeric heterochromatin assembly and telomere length. Nucleic Acids Research 42:11419-11432. doi: 10.1093/nar/gku842.

Wang J, Tadeo X, Hou H, Tu PG, Thompson J, Yates JR III, Jia S. 2013. Epe1 recruits BET family bromodomain protein Bdf2 to establish heterochromatin boundaries. Genes \& Development 27:1886-1902. doi: 10.1101/gad. 221010.113.

Wang Y, Kallgren SP, Reddy BD, Kuntz K, Lopez-Maury L, Thompson J, Watt S, Ma C, Hou H, Shi Y, Yates JR III, Bähler J, O'Connell MJ, Jia S. 2012. Histone H3 lysine 14 acetylation is required for activation of a DNA damage checkpoint in fission yeast. The Journal of Biological Chemistry 287:4386-4393. doi: 10.1074/jbc.M111.329417.

Watt S, Mata J, Lopez-Maury L, Marguerat S, Burns G, Bahler J. 2008. urg1: a uracil-regulatable promoter system for fission yeast with short induction and repression times. PLOS ONE 3:e1428. doi: 10.1371/journal.pone. 0001428.

Yamanaka S, Mehta S, Reyes-Turcu FE, Zhuang F, Fuchs RT, Rong Y, Robb GB, Grewal SI. 2013. RNAi triggered by specialized machinery silences developmental genes and retrotransposons. Nature 493:557-560. doi: 10.1038/ nature11716.

Zhang K, Mosch K, Fischle W, Grewal SI. 2008. Roles of the Clr4 methyltransferase complex in nucleation, spreading and maintenance of heterochromatin. Nature Structural \& Molecular Biology 15:381-388. doi: 10. 1038/nsmb.1406.

Zofall M, Grewal SI. 2006. Swi6/HP1 recruits a JmjC domain protein to facilitate transcription of heterochromatic repeats. Molecular Cell 22:681-692. doi: 10.1016/j.molcel.2006.05.010.

Zofall M, Yamanaka S, Reyes-Turcu FE, Zhang K, Rubin C, Grewal SI. 2012. RNA elimination machinery targeting meiotic mRNAs promotes facultative heterochromatin formation. Science 335:96-100. doi: 10.1126/science. 1211651. 